\title{
Stylomastoid foramen osteoma unique challenges for appropriate management
}

\begin{abstract}
Osteoma of the temporal bone is a rare and slow-growing benign tumor. It is reported to affect almost all portions of the temporal bone. However, osteoma involving the stylomastoid foramen has never been reported in the literature. We report a case of an osteoma extending from the stylomastoid foramen and occluding the EAC in a young female. Although the osteoma has very close relationship with the facial nerve, it was removed because of the severity of its associated symptomatology; the osteoma was completely removed without any postoperative complications. This report is of interest as it highlights the challenges in the management of osteomas in such localization.
\end{abstract}

Keywords: osteoma, temporal bone, stylomastoid foramen, facial nerve
Volume 3 Issue 2 - 2015

\begin{abstract}
Hassan Haidar, Sally Sheta, Aisha Larem
Department of Otolaryngology Hamad Medical Corporation, Qatar
\end{abstract}

Correspondence: Hassan Haidar Otolaryngology department Hamad Medical Corporation, Doha-Qatar Email Hahmad2@hamad.q.a

Received: June 01, 2015 | Published: September 15, 2015

\section{Introduction}

Osteomas are benign bone neoplasms. In the head and neck region, they are usually found in thefrontoethmoid area., ${ }^{1,2}$ Temporal bone osteoma is a rare entity, ${ }^{3}$ and when this occurs, it is most commonly seen in the external auditory canal (EAC). A mastoid osteoma is even more infrequent. ${ }^{4}$ Osteomas are usually asymptomatic $;{ }^{5}$ in symptomatic cases, treatment of the osteoma is surgical, but in symptomatic cases involvingnoble structures, the management can be challenging. In this report, we present a case of a 43year old female patient with a large osteoma extending from the stylomastoid foramen (SMF) and filling the EAC and we discuss the challenges regarding the treatment of this lesion.

\section{Case report}

A 43year old female, previously healthy, was referred to our center due to a long-standing history of right recurrent otitis externa that become very frequent and invalidating. She reports also progressive right sided hearing loss. There were no accompanying symptoms ofvertigo or tinnitus in her medical history. Otolaryngologic examination revealed a hard, immobile, mildly tender mass with erythematous overlying skin filling the right EAC, occluding view to the tympanic membrane. The left ear was normal. Facial nerve examination was intact bilaterally. No other masses were palpated in the head and neck region. On audiogram, right conductive hearing loss was revealed. A temporal bone CT scan indicated a well demarcated, dense, sclerotic mass of approximately $2.3 \times 2 \mathrm{~cm}$ of the right mastoid process filling the EAC and extending inferiorly to the SMF, the mass was very near but not involving the mastoid segment of the fallopian canal. The middle and inner ear were normal. The radiologic appearance was suggestive of osteoma (Figure 1). Because of the severity of her symptoms, especially severe and refractory otitis externa, the patient was asking for definitive treatment. An extensive discussion was done with her on the risk of facial nerve injury because of the critical localization of the lesion. The patient accepted the risk and signed a medical consent of high risk of postoperative facial palsy.

The resection of tumor was performed using posterior transmastoid approach (Figure 2). After a cortical mastoidectomy, the mastoid segment of the facial nerve was identified and followed down till the SMF. The osteoma was identified in the anteroinferior part of the mastoid process about $1 \mathrm{~mm}$ lateral to the fallopian canal; the posterior and inferior walls of the EAC were replaced by the tumor which was filling the lateral part of the EAC and extending inferiorly on the vaginal process till the base of styloid process. A gradual drilling around the tumor was performed, taking care of the proximity of the facial nerve, till the mass was complete excised en bloc. Reconstruction of the EAC was done using tragal cartilage and fascia that was covered by the remaining skin. The canal was dressed with gauze with antibiotic and corticoid unguent for 2 weeks (Figure 2 ). The postoperative period was smooth, facial nerve function was intact. Three weeks later, the EAC dressing was removed; the canal was patent and wide and completely epithelized. Histopathology result confirmed the diagnosis of osteoma (Figure 3).
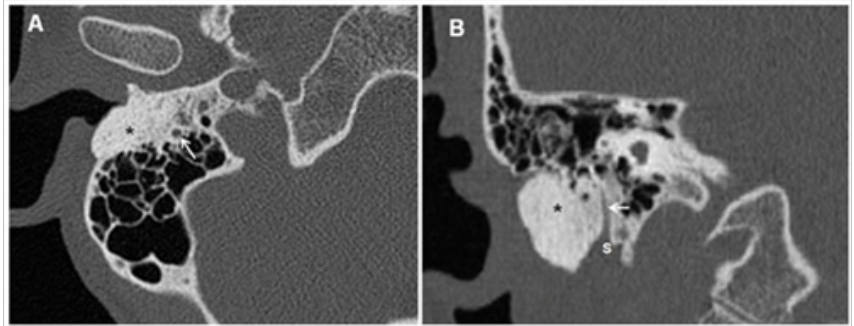

Figure I Right Temporal bone CT scan, Axial cut (A) and saggital cut (B) showing a hyperdense bony mass $(\mathrm{O})$ occluding the ear canal extending posteriorly into the mastoid in close relationship with the facial nerve(white arrow) and inferiorly to the stylomastoid foramen (S).
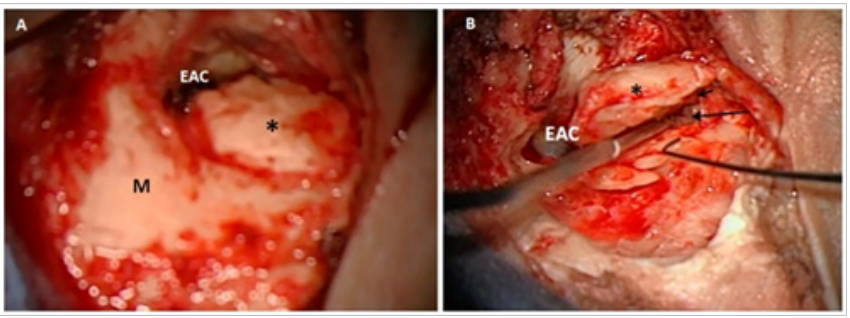

Figure 2 Operative view of posterior approach of right ear. A: a big osteoma $(*)$ filling the ear canal (EAC) and extending to the mastoid cortex $(M)$ and extending inferiorly. B: after cortical mastoidectomy, the mastoid facial nerve is identified till its emergence from the stylomastoid foramen(long arrow); osteoma $(*)$;styloid process (short arrow).

\section{Discussion}

Temporal bone osteomas are very rare benign osteogenic tumors. When they occur, they are seen most commonly in the EAC. Here 
they arise from the site lateral to the isthmus of the EAC, with its base is located at the tympanosquamous or tympanomastoid suture lines adjacent to the bony-cartilaginous junction in most cases. An osteoma originates from the preosseous connective tissue in these suture lines as they have a thicker subcutaneous layer and a richer blood supply than the other parts of the bony canal. Canalicular osteomas are usually localized to the external auditory canal; however, canalicular osteomas extending to the stylomastoid foramen have never been reported in literature.

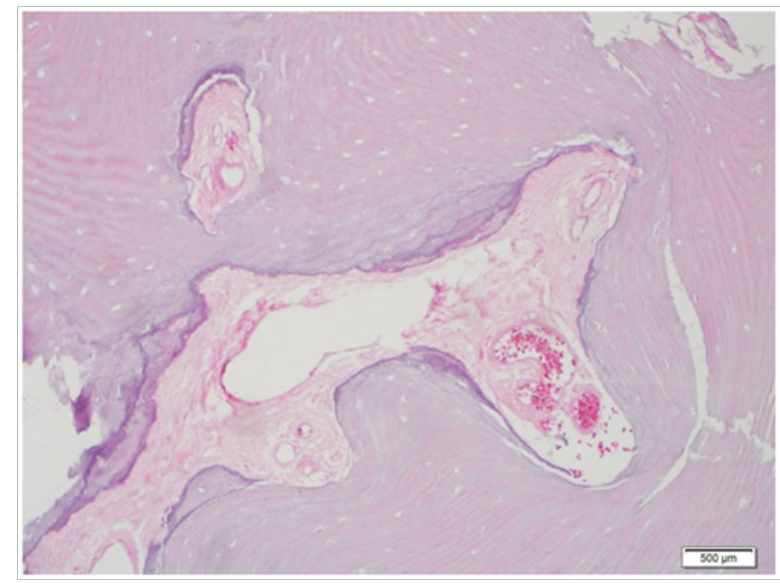

Figure 3 Microscopic description:'Sections show dense, mature, predominantly lamellar bone. Interosseous space is mostly composed of scant fibrovascular tissue.

Although an osteoma of the EAC grows slowly and remains stable for many years, symptoms such as conductive hearing impairment or recurrent infection can arise if the osteoma grows to a point of canal obstruction. Hearing loss occurs due to retention of epithelial residues and wax, rather than mechanical obstruction of the conductive passage by the tumor. A secondary cholesteatoma can ensue. ${ }^{6}$ Diagnosis is usually confirmed by CT scan where osteomas appear as a well circumscribed mass with soft tissue density, egg-shell like density or bone density.

The main treatment for an EAC osteoma is a surgical excision. The size and location of the osteoma as well as the severity of symptoms determine the treatment. Patients with a small osteoma and little or no symptoms may be treated in a conservative manner. Surgical excision is recommended if a growing osteoma results in occlusion of the canal and the patient complains ofrecurrent infection and/or conductive hearing impairment. When the osteoma is located at the lateral portion and is a peduncular type, it can be easily removed by an osteotome or drilling through the transmeatal approach. When an osteoma is located medial to the isthmus, is huge, or has a broad base, it is safe to remove it through the postauricular approach. ${ }^{7-11}$ However, for cases with a large posterior wall defect the canal wall down mastoidectomy or canal wall up mastoidectomy with posterior wall reconstruction can be used. ${ }^{12,13}$

It is reported that in cases of osteomas extending into the fallopian canal, complete excision is not indicated since there is risk of damage to the facial nerve. ${ }^{14}$ However, it is reported also that partial surgical excision by drilling on the tumor tissue may result in recurrence of tumor that may grow medially to encroach on vital structures making potential future revision excision challenging. ${ }^{14}$ The definitive treatment of osteoma remains of complete resection by drilling around the osteoma and avoiding damage to vital structures. ${ }^{15}$ In this case, the patient had a huge osteoma occluding almost the entire EAC and an extensive extension posteriorly and inferiorly in a close relationship with the mastoid segment of the fallopian canal till the SMF. Therefore, a canal wall up mastoidectomy and identification of the mastoid segment of the facial nerve from the second genu till the SMF was done first before resection of the osteoma; the inferior and posterior wall of the auditory canal was reconstructed using cartilage.

\section{Acknowledgments}

None.

\section{Conflicts of interest}

Author declares there are no conflicts of interest.

\section{Funding}

None.

\section{References}

1. Probst LE, Shankar L, Fox R. Osteoma of the mastoid bone. $J$ Otolaryngol. 1991;20(3):228-230.

2. Burton DM, Gonzalez C. Mastoid osteomas. Ear Nose Throat J. 1991;70(3):161-162.

3. Unal OF, Tosun F, Yetișer S, et al.Osteoma of the middle ear. Int $J$ Pediatr Otorhinolaryngol. 2000;52(2):193-195.

4. Lt Col AK Das, GP Capt RC Kashyap. Osteoma of the mastoid bone-a case report. 2005; 61:86-87.

5. Güngör A, Cincik H, Poyrazoglu E, et al. Mastoid osteomas: report of two cases. Otol Neurotol . 2004;25(2):95-97.

6. Fenton JE, Turner J, Fagan PA. A histopathologic review of temporal bone exostoses and osteomata. Laryngoscope. 1996;106(5 Pt 1):624-628

7. Graham MD. Osteomas and exostoses of the external auditory canal. A clinical, histopathologic and scanning electron microscopic study. Ann Otol Rhinol Laryngol. 1979;88(4 Pt 1):566-572.

8. Tran LP, Grundfast KM, Selesnick SH. Benign lesions of the external auditory canal. Otolaryngol Clin North Am. 1996;29(5):807-825.

9. Fisher EW, McManus TC. Surgery for external auditory canal exostoses and osteomata. J Laryngol Otol. 1994;108(2):106-110.

10. Sheehy JL. Diffuse exostoses and osteomata of the external auditory canal: a report of 100 operations. Otolaryngol Head Neck Surg. 1982;90(3 Pt 1):337-342.

11. Yamamoto E, Iwanaga M, Sato K. Osteoma with cholesteatoma in the external auditory canal. Practica Otol. 1986;79(4):575-578.

12. Orita Y, Nishizaki K, Fukushima K, et al. Osteoma with cholesteatoma in the external auditory canal. Int $J$ Pediatr Otorhinolaryngol. 1998;43(3):289-293.

13. Vrabec JT, Chaljub G. External canal cholesteatoma. Am J Otol. 2000;21(5):608-614.

14. Mustafa A. Osteoma of mastoid process obstructing external auditory canal: A case report. Health. 2012;4(4):222-224.

15. Viswanatha B. Characteristics of osteoma of the temporal bone in young adolescents. Ear Nose Throat J. 2011:90(2):72-79. 